Cite this: Phys. Chem. Chem. Phys., 2013, 15, 11014

Received 8th June 2012, Accepted 8th May 2013 DOI: $10.1039 / c 3 c p 42104 j$ www.rsc.org/pccp

\section{Different formation kinetics and photoisomerization behavior of self-assembled monolayers of thiols and dithiolanes bearing azobenzene moieties}

\author{
Chun L. Yeung, $\dagger^{\mathrm{a}}$ Scott Charlesworth, $\dagger^{\mathrm{ab}}$ Parvez Iqbal, ${ }^{\mathrm{a}}$ James Bowen, ${ }^{\mathrm{a}}$ \\ Jon A. Preece ${ }^{b}$ and Paula M. Mendes*a
}

\begin{abstract}
Self-assembled monolayers (SAMs) containing azobenzene moieties are very attractive for a wide range of applications, including molecular electronics and photonics, bio-interface engineering and sensoring. However, very little is known about the aggregation and photoswitching behavior that azobenzene units undergo during the SAM formation process. Here, we demonstrate that the formation of thiolbased SAMs containing azobenzenes (denoted as AzoSH) on gold surfaces is characterised by a twostep adsorption kinetics, while a three-step assembly process has been identified for dithiolane-based SAMs containing azobenzenes (denoted AzoSS). The H-aggregation on the AzoSS SAMs was found to be remarkably dependent on the time of self-assembly, with less aggregation as a function of time. While photoisomerization of the AzoSH was suppressed for all different assembly times, the reversible trans-cis photoisomerization of AzoSS SAMs formed over 24 hours was clearly observed upon alternating UV and Vis light irradiation. We contend that detailed information on formation kinetics and related optical properties is of crucial importance for elucidating the photoswitching capabilities of azobenzenebased SAMs.
\end{abstract}

\section{Introduction}

Photo-switchable self-assembled monolayers (SAMs) have been receiving considerable attention, motivated by their potential applications in molecular electronics and photonics, bio-interface engineering, catalysis and sensoring. ${ }^{1-4}$ One of the most frequently studied classes of photo-switchable molecules is the azobenzenecontaining molecules, since the azobenzene moiety is known to undergo cis-trans isomerism. ${ }^{5}$ Photoisomerization from the thermodynamically more stable trans isomer to the cis isomer and vice versa can be selectively induced by irradiation with either ultraviolet (UV) light or visible (Vis) light. The free volume required for the cis form is larger than for the trans form assuming either an inversion or a rotation mechanism of the azo bond. ${ }^{6-8}$ Thus, photoisomerization rates strongly depend on the local free volume available for the conformation change. In this regard, an azobenzene-terminated alkanethiol SAM hardly

\footnotetext{
${ }^{a}$ School of Chemical Engineering, University of Birmingham, Edgbaston, Birmingham, B15 2TT, UK. E-mail: p.m.mendes@bham.ac.uk; Tel: +44 (0)121-414-5343

${ }^{b}$ School of Chemistry, University of Birmingham, Edgbaston, Birmingham, B15 2TT, UK

$\dagger$ These authors contributed equally to this work.
}

exhibits any photoisomerization owing to the existence of both $\mathrm{H}$-aggregation and spatial constraints. ${ }^{9-11}$ Regarding the former, neighboring azobenzenes have a high tendency to form head-tohead H-aggregates in a SAM due to $\pi-\pi$ stacking interactions, leading to a dense molecular packing, that suppresses azobenzene photoisomerization. $^{10}$

Efforts have been made to increase the spacing between the azobenzene moieties in order to promote the reversible transto-cis photoisomerization process in SAMs on gold. ${ }^{12-21}$ Photoswitching of azobenzene SAMs has been achieved by employing asymmetrical disulfides, ${ }^{12}$ asymmetrical thioethers, ${ }^{13}$ bulky alkyl groups into the benzene ring of the azobenzene unit, ${ }^{14-16}$ or by inclusion of a bulky carborane unit para to the diazo functionality in order to space out the backbones. ${ }^{17}$ Other strategies relied on azobenzene derivatives with bulkier terminal headgroups than thiols, including a tripodal adamantane-based thioacetate headgroup $^{18}$ an asparagusic acid-based 1,2-dithiolane headgroup ${ }^{19}$ and an $\alpha$-lipoic acid-based 1,2-dithiolane headgroup. ${ }^{21}$ Regarding the latter, no photoisomerization was observed when the molecules were absorbed from the trans isomer, whereas molecules adsorbed in cis configuration were photoreactive. The inhibition of structural arrangement associated with trans-cis isomerization when the molecules were absorbed from the trans isomer is most 
probably due to hydrogen bonds between the amide groups by which the azobenzene moieties were attached to the dithiolane headgroup moiety. ${ }^{21}$ Although SAMs of an azobenzene terminated dithiolane analogue, in which the amide group in the spacer was replaced by an ester moiety, were prepared by the same authors, ${ }^{21}$ no photoisomerization studies were conducted. Thus, the photoisomerization capabilities of $\alpha$-lipoic acid-based SAMs containing azobenzene moieties are not fully understood and remain to be further investigated. Furthermore, in this study and others, ${ }^{17-21}$ little attention has been paid to the aggregation and photoswitching behavior that azobenzene units undergo during the SAM formation process. Single monolayer formation times have been used for accessing the switching of SAMs containing azobenzene moieties and times of formation have been varied from $0.5 \mathrm{~h}$ to $24 \mathrm{~h}^{17,18,20,21}$

Stimulated by the lack of information in certain aspects of azobenzene-based SAMs as discussed above, in this study we investigate in detail monolayers formed from an $\alpha$-lipoic acidbased azobenzene (AzoSS, Fig. 1), in which an ester linkage is incorporated into the chain between the $\alpha$-lipoic acid and the azobenzene, and a thiol-based azobenzene analogue (AzoSH, Fig. 1), in which the $\alpha$-lipoic acid is replaced by an alkanethiol which is linked to the azobenzene using an ether bond. The goal of this work is to extend our knowledge on azobenzenebased SAMs, to answer two principal questions. First, how does $\mathrm{H}$-aggregation and the optically induced switching depend on the time of SAM formation, and are these properties dependent on the headgroup? Second, are $\alpha$-lipoic acid-based azobenzene SAMs capable of undergoing reversible photoisomerization in the absence of hydrogen bonding on the SAM structure? The adsorption kinetics of the AzoSS and AzoSH SAMs are studied by means of contact angle, ellipsometry, surface plasmon resonance (SPR) spectroscopy and X-ray photoelectron spectroscopy (XPS). The relation between time of SAM formation and its effect on $\mathrm{H}$-aggregation and photoswitching capabilities for both SAMs, AzoSH and AzoSS SAMs, is also ascertained by UV/Vis spectroscopy using the spectroscopic characteristics of the azo chromophores in the cis and trans conformations.

\section{Results and discussion}

Two new azobenzene derivatives, AzoSs and AzoSH were synthesized as outlined in Fig. 1. Synthesis of Azoss was initiated through diazotisation of the 4-aminobenzoic acid tert-butyl ester, which was reacted with phenol under basic conditions to give the azobenzene $\mathbf{1}$. The azobenzene $\mathbf{1}$ was coupled with thioctic acid using $N, N^{\prime}$-dicyclohexylcarbodiimide (DCC) in the presence of 4-dimethylaminopyridine (DMAP) to afford the Azoss. The synthesis of AzoSH involved initial formation of the thioacetate 2 via thioacetylation of 6-bromo1-hexene in the presence of $\mathrm{CH}_{3} \mathrm{COSH}$ and the radical initiator, 2,2'-azobisisobutyronitrile (AIBN), followed by alkylation with the phenoxide moiety in $\mathbf{1}$, to form the azobenzene thioacetate $\mathbf{3}$. Subsequently, the thioacetate $\mathbf{3}$ was hydrolysed under acidic conditions to obtain the desired AzoSH. These hydrolysis conditions did not hydrolyse the tert-butyl ester group.

Fig. 2 shows the UV absorption spectra of AzoSS and AzoSH in ethanol $(0.0625 \mathrm{mM})$ before and after irradiation with UV (365 $\mathrm{nm})$ and subsequent visible light irradiation (436 nm). Typical of azobenzene derivatives, the trans form is more stable and is the dominant isomer before UV irradiation. The trans form of AzoSS exhibits a strong $\pi-\pi^{*}$ absorption peak with a maximum wavelength $\left(\lambda_{\max }\right)$ at $329 \mathrm{~nm}$ and a weak $\mathrm{n}-\pi^{*}$ band at around $445 \mathrm{~nm}$. The corresponding bands for the trans form of AzoSH are found at $360 \mathrm{~nm}$ and $445 \mathrm{~nm}$. Thus, the $\lambda_{\max }$ of the $\pi-\pi^{*}$ absorption band is influenced by the linking functionality (i.e. ether or ester group) between the azobenzene and the

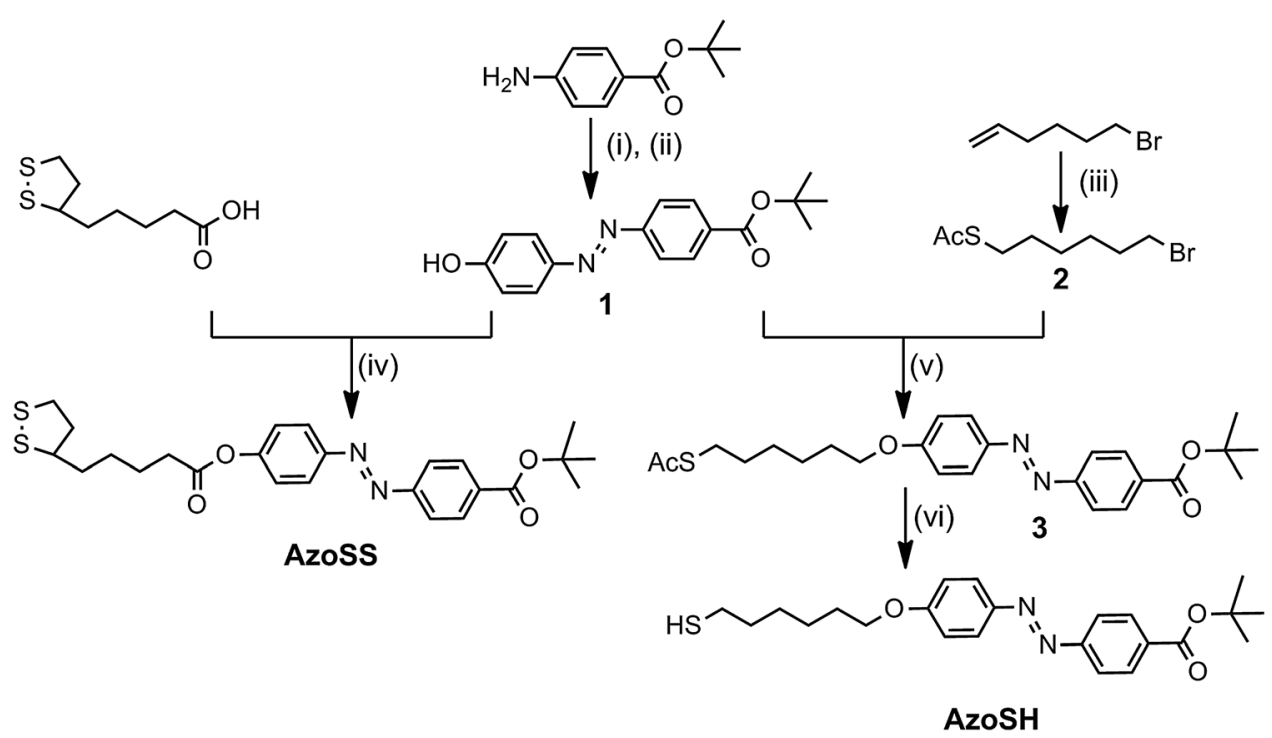

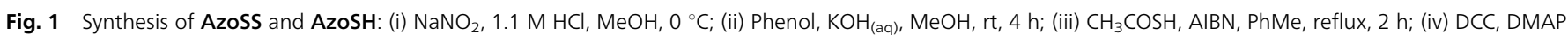
(cat), DCM, rt, $\mathrm{N}_{2(\mathrm{~g})}$ atm, $16 \mathrm{~h}$; (v) $\mathrm{K}_{2} \mathrm{CO}_{3}$, acetone, refluxed, $16 \mathrm{~h}$; (vi) $0.1 \mathrm{M} \mathrm{HCl}, \mathrm{MeOH}$, reflux, $\mathrm{N}_{2(\mathrm{~g})}$ atm, $4 \mathrm{~h}$. 

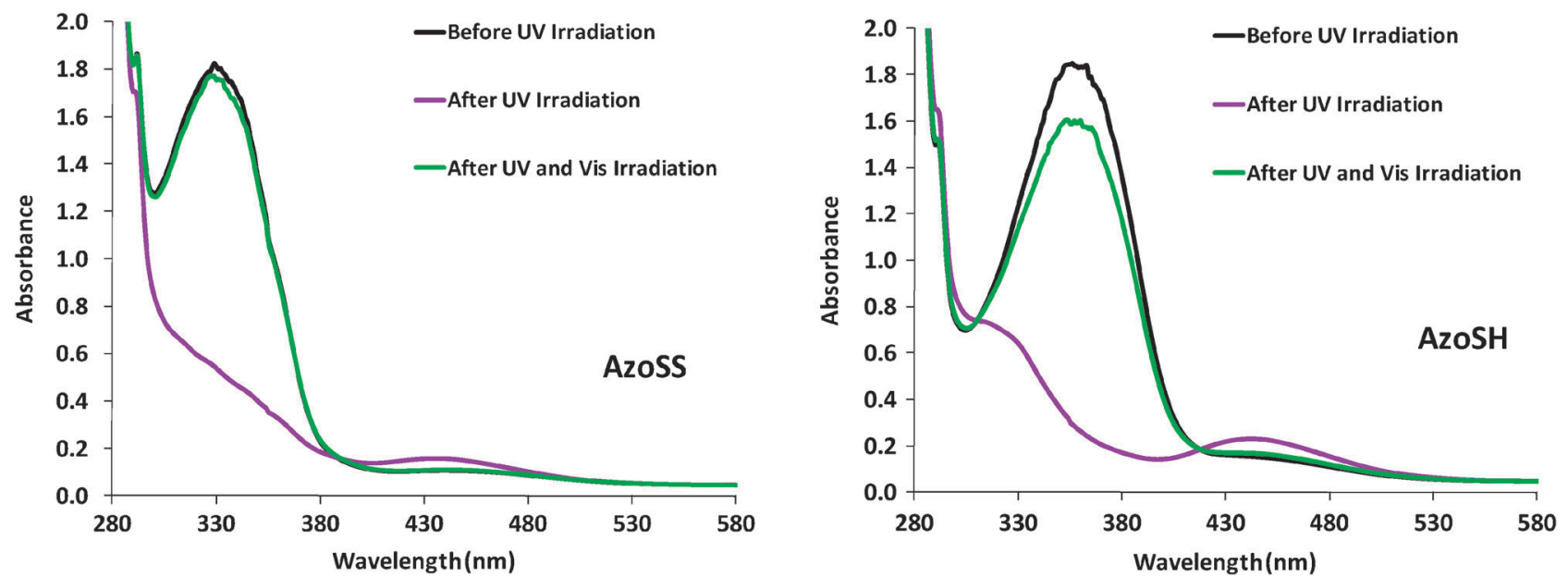

Fig. 2 UV/Vis absorption spectra of AzoSS and AzoSH in ethanol before and after UV and Vis irradiation. UV irradiation at $365 \mathrm{~nm}$ led to trans $\rightarrow$ cis isomerization, whereas Vis irradiation at $436 \mathrm{~nm}$ drove the back reaction (cis $\rightarrow$ trans).

headgroup, with $\lambda_{\max }$ of the AzoSH being bathochromically shifted by $25 \mathrm{~nm}$ with respect to that of AzoSS. For both compounds, AzoSS and AzoSH, upon UV irradiation for $1 \mathrm{~min}$, a drastic reduction in the $\pi-\pi^{*}$ band is observed, whereas the $n-\pi^{*}$ becomes more intense. These results suggest that the azobenzene molecules are converted into cis isomers in both solutions. Subsequent visible light irradiation for $1 \mathrm{~min}$ gives rise to cis to trans isomerization, maximizing the $\pi-\pi^{*}$ absorption band. Although the cis to trans isomerization is fully reversible for the AzoSS molecule, the AzoSH molecule displays slightly less reversible behaviour. This photoequilibrium composition remained unchanged even after the irradiation was prolonged to $5 \mathrm{~min}$.

SAM formation was evaluated using ellipsometry, contact angle and XPS (Fig. 3-5) after $24 \mathrm{~h}$ immersion time of a cleaned gold substrate in a $0.0625 \mathrm{mM}$ ethanolic solution of AzoSS or AZoSH. The ellipsometric thicknesses of the fully formed SAMs are $1.8 \mathrm{~nm}$ (AzoSS) and $1.6 \mathrm{~nm}$ (AzoSH), and both are less than the theoretical molecular length of the molecules (both $2.5 \mathrm{~nm}$ ). This discrepancy, between molecular length and SAM thickness, is expected and is in agreement with the literature, being ascribed to both the tilt angle and density of the SAM surfactants. ${ }^{22,23}$ The advancing $\left(\theta_{\text {Adv }}\right)$ and receding $\left(\theta_{\text {Rec }}\right)$ contact angles for AzoSS $\left(\approx 90^{\circ}\right.$ and $\approx 75^{\circ}$, respectively $)$ and AzoSH $\left(\approx 90^{\circ}\right.$ and $\approx 80^{\circ}$, respectively) are in good agreement with the literature ${ }^{24,25}$ for tert-butyl ester SAMs, noting that the final hysteresis values $\left(\theta_{\mathrm{Adv}}-\theta_{\mathrm{Adv}}\right)$ of AzoSS $\left(\sim 15^{\circ}\right)$ are slightly larger than AzoSH $\left(10^{\circ}\right)$ indicating a less dense packed SAM for AzoSS. XPS analysis confirms the presence of the elemental species N, C, O and S on the AzoSS SAMs (Fig. 5). The single peak at $400.5 \mathrm{eV}$ in the $\mathrm{N}(1 \mathrm{~s})$ spectrum is assignable to the nitrogen of the azo group. ${ }^{16}$ The C (1s) spectrum can be deconvoluted into three peaks, which are attributed to five different binding environments (Fig. 5). The main, predominant peak $(284.7 \mathrm{eV})$ is attributed to $\mathrm{C}-\mathrm{C}$ bonds ${ }^{26}$ within both the alkyl chains and phenyl rings. The first of the two smaller peaks $(286.4 \mathrm{eV})$ is attributed to $\mathrm{C}(1 \mathrm{~s})$ of the three binding environments of $\mathrm{C}-\mathrm{S}, \mathrm{C}-\mathrm{N}$ and $\mathrm{C}-\mathrm{O}-\mathrm{C}^{26}$ The third and final peak $(288.7 \mathrm{eV})$ is attributed to the $\mathrm{C}(1 \mathrm{~s})$ photoelectron of the carbonyl moiety, $\mathrm{C}=\mathrm{O}^{26}$ The $\mathrm{O}(1 \mathrm{~s})$ spectra are de-convoluted into two different peaks, corresponding to two different binding environments, arising from the ester moieties, $\mathrm{C}-\mathrm{O}-\mathrm{C}(533.9 \mathrm{eV})$ and the carbonyl oxygen $\mathrm{C}=\mathrm{O}(532.3 \mathrm{eV}) .{ }^{26}$ The $\mathrm{S}(2 \mathrm{p})$ spectrum displays a doublet structure at $163.6 \mathrm{eV}\left(\mathrm{S}\left(2 \mathrm{p}_{1 / 2}\right)\right)$ and $162.4 \mathrm{eV}$ (S $\left(2 \mathrm{p}_{3 / 2}\right)$ ), which is assignable to the thiolate-type sulfur bound to the gold surface as previously reported for SAMs using a 1,2-dithiolane headgroup. ${ }^{21}$ The AzoSH SAMs exhibit similar $\mathrm{N}$ (1s) and S (2p) spectra (Fig. 5). The C (1s) and $\mathrm{O}(1 \mathrm{~s})$ are also similar, but with lower intensities for the C (1s) peak at $288.7 \mathrm{eV}$ and $\mathrm{O}(1 \mathrm{~s})$ at $532.3 \mathrm{eV}$ due to the absence of the second carbonyl moiety on the AzoSH molecule.

The kinetics of formation of the AzoSS and AzoSH SAMs was investigated by ellipsometry and contact angle. SAMs were formed by immersion of freshly cleaned Au substrates in $0.0625 \mathrm{mM}$ ethanolic solutions of either AzoSS or AzoSH for $0.5 \mathrm{~h}, 1.5 \mathrm{~h}, 3 \mathrm{~h}, 6 \mathrm{~h}, 9 \mathrm{~h}, 18 \mathrm{~h}, 21 \mathrm{~h}, 24 \mathrm{~h}$ and 48 h, followed by rinsing with ethanol. Ellipsometric thickness and contact angles $\left(\theta_{\mathrm{Adv}}\right.$ and $\left.\theta_{\mathrm{Rec}}\right)$ were recorded for each time interval (Fig. 3 and 4). In the case of AzoSS monolayers, three distinct SAM formation stages can be discerned in both Fig. 3 and 4 when considering the ellipsometric thickness and the $\theta_{\text {Rec }}$ angle, which is significantly different to a simple alkyl thiol and indeed the AzoSH growth kinetics (see later). These stages occur between 0 and $6 \mathrm{~h}$ (Stage I), 6 and $21 \mathrm{~h}$ (Stage II) and after $21 \mathrm{~h}$ (Stage III). Considering the very initial stage (Stage I), the thickness rises to $\approx 2.4 \mathrm{~nm}$ within $0.5 \mathrm{~h}$ and subsequently drops to $1.2 \mathrm{~nm}$ over the first $6 \mathrm{~h}$. Over the next $15 \mathrm{~h}$, the AzoSS SAM undergoes a growth in thickness, as might be expected for SAM formation (Stage II). Finally, after $21 \mathrm{~h}$ the thickness plateaus at $\approx 1.8 \mathrm{~nm}$, indicating that the SAM is fully formed (Stage III).

In contrast, for AzoSH there is no Stage I as for AzoSS, and the SAM thickness rises to $\approx 0.80 \mathrm{~nm}$ within $0.5 \mathrm{~h}$ and then to $\approx 1.2 \mathrm{~nm}$ by $6 \mathrm{~h}$ and reaches a plateau of $\approx 1.6 \mathrm{~nm}$ by $24 \mathrm{~h}$, 


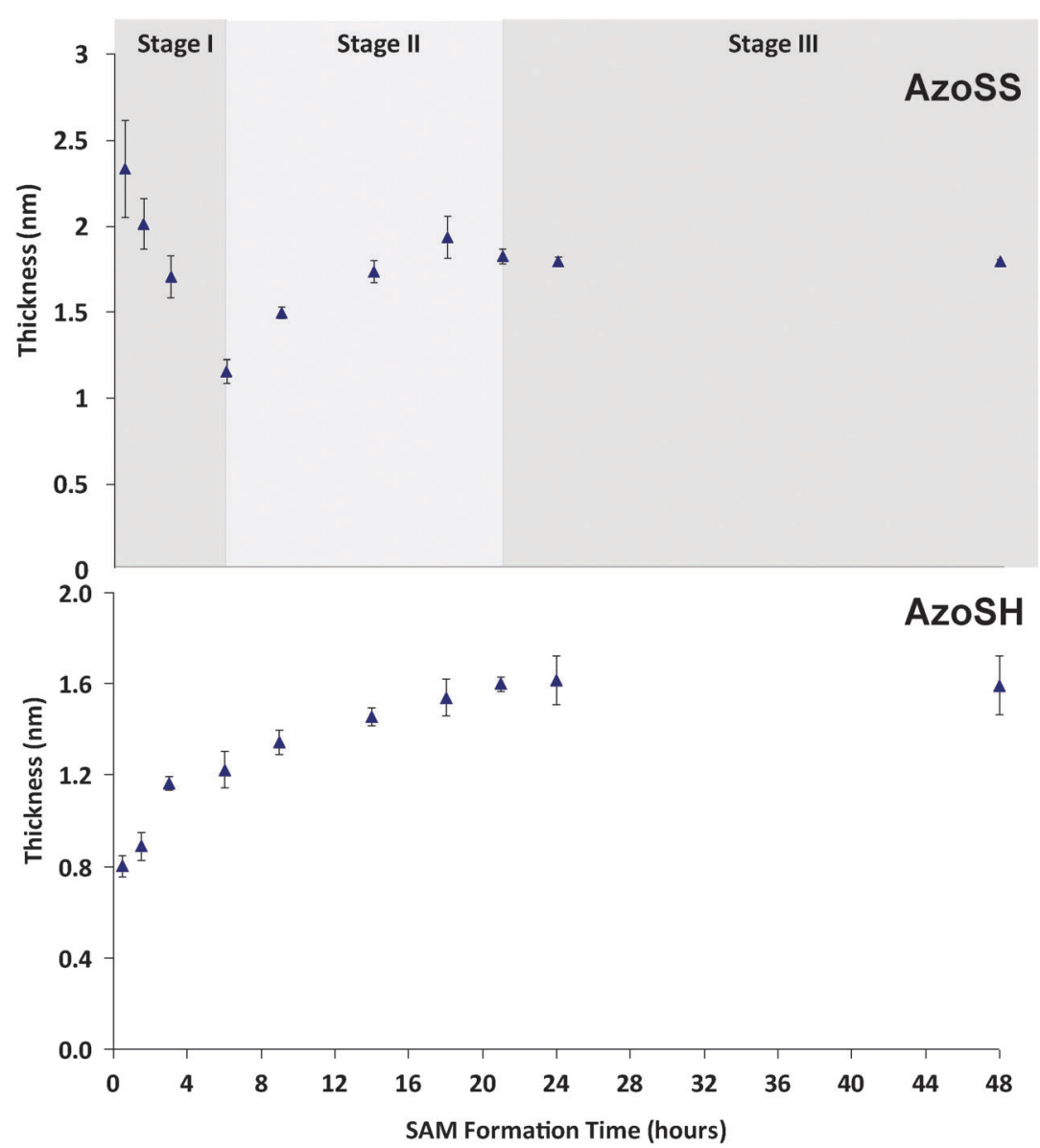

Fig. 3 Ellipsometry kinetic study, thickness versus the formation time for AzoSS and AzoSH SAMs prepared by immersion of a clean gold substrate into the sample solution for 0.5 h, 1.5 h, 3 h, 6 h, 9 h, 18 h, 21 h, 24 h and 48 h.

following standard alkyl thiol growth kinetics. ${ }^{27}$ This two-stage adsorption behavior of AzoSH is also in agreement with adsorption kinetic studies conducted by Tamada et $a l .{ }^{11}$ on azobenzenecontaining alkanethiol SAMs on gold. As a control, and to rule out the initial increase in thickness of the Azoss surface we considered that a bare $\mathrm{Au}$ surface is a relatively high energy surface and is prone to the physisorption of airborne contaminants. $^{27}$ Thus, we carried experiments without the AzoSS in the solution and measured the ellipsometric thickness after several time intervals over $6 \mathrm{~h}$, which showed the ellipsometric thickness of the contaminant layer to be $\approx 1.24 \mathrm{~nm}$, irrespective of immersion time. This thickness is lower than the values observed $(2.4 \mathrm{~nm})$ within the first $4 \mathrm{~h}$ of SAM formation with Azoss, and hence Stage I in Fig. 3 cannot be attributed to the non-specific physisorption of airborne contaminants.

The $\theta_{\text {Rec }}$ angles of the Azoss reveal similar three stage behavior to the ellipsometric data. The $\theta_{\text {Rec }}$ reaches $\approx 65^{\circ}$ within $0.5 \mathrm{~h}$, and then decreases to $\approx 35^{\circ}$ over $1.5 \mathrm{~h}$ (Stage I), then increases to $\approx 70^{\circ}$ over the following $4.5 \mathrm{~h}$ (Stage II), and remains constant for the next $12 \mathrm{~h}$ (Stage III), suggesting the presence of a more sparsely packed monolayer at $24 \mathrm{~h}$, as indicated by a large hysteresis of $\sim 15^{\circ}\left(\theta_{\mathrm{Adv}}-\theta_{\mathrm{Rec}}\right)$ relative to AzoSH. In contrast the AzoSH $\theta_{\text {Rec }}$ angle increases consistently over the SAM formation time, starting at $\sim 75^{\circ}$ and reaching a plateau after $21 \mathrm{~h}$ at $\sim 80^{\circ}$, giving a final smaller hysteresis of $10^{\circ}\left(\theta_{\mathrm{Adv}}-\theta_{\mathrm{Rec}}\right)$, indicating a more ordered and packed monolayer structure than the Azoss.

Label-free sensing technologies such as SPR and quartz crystal microbalance (QCM) allow for real-time monitoring of adsorption processes and kinetics. ${ }^{28-30}$ Thus, in addition to the ellipsometry and contact angle measurements, we have carried out SPR analysis in order to monitor the adsorption kinetics of the AzoSS and AzoSH onto the gold surfaces (Fig. 6). The SPR baseline for the clean gold chips was established using ethanol, following which the AzoSS or AzoSH in ethanol (0.0625 mM) was introduced into the SPR flow cell at the rate of $10 \mu \mathrm{L} \mathrm{min}^{-1}$ (Fig. 6). Data were collected for $21 \mathrm{~h}$, followed by washing with ethanol. SPR reveals clear differences in the kinetics of monolayer formation for AzoSS and AzoSH SAMs. The AzoSS SAM formation proceeds through three stages. In Stage I (0-2.3 h), an initial adsorption of molecules on the surface that peaks at 1950 response units is followed by a $15 \%$ decrease in the SPR signal after 30 minutes. This decrease suggests a significant level of desorption of molecules from the gold surface. After Stage I, the formation kinetics proceeds into two more stages Stage II and Stage III. Stage II occurs between $2.3 \mathrm{~h}$ and 6.6 hours and Stage III from 6.6 hours to the time the rinsing is initiated. Both stages are characterised by an initial increase 


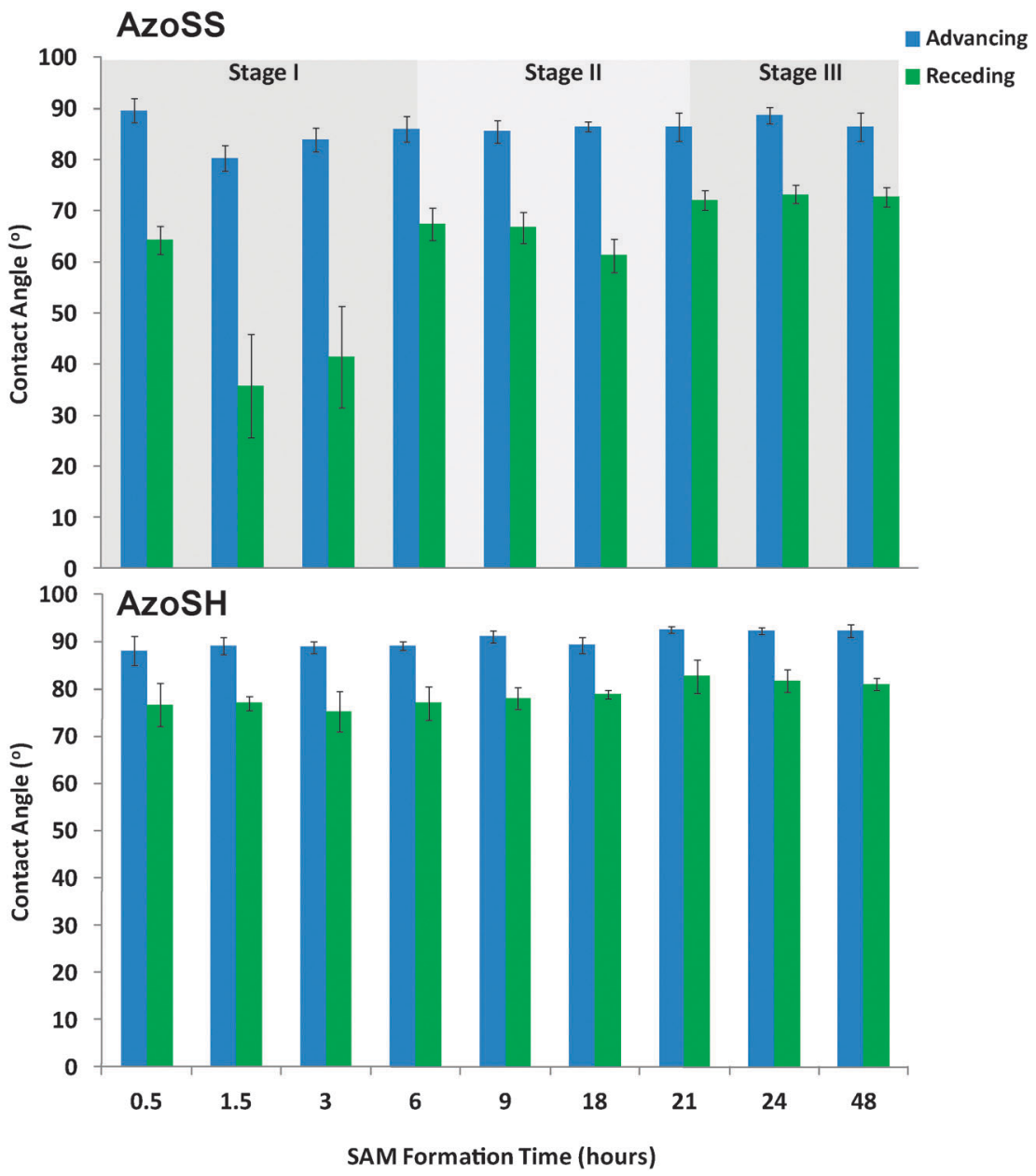

Fig. 4 Water contact angle kinetics of AzoSS and AzoSH SAMs.

in the amount of AzoSS on the surface, evidenced by the increase in the SPR response units, that plateaus for Stage II and Stage III after $1.5 \mathrm{~h}$ and $3 \mathrm{~h}$, respectively. When ethanol replaces the AzoSS solution, there is a significant drop in the SPR signal to 1980 response units, indicating the removal of a significant amount of non-chemisorbed AzoSS molecules from the surface.

The AzoSH SAM formation proceeds through a two stage process, involving a rapid initial adsorption of AzoSH on the surface followed by a much slower adsorption that plateaus at $\sim 3330$ response units. After contact with the AzoSH thiol solution is finished, the signal decreases slightly with only a small amount of AzoSH being removed from the surface.

These distinct stages between the kinetics of SAM formation of the AzoSS and AzoSH, as shown in the ellipsometric (Fig. 3), contact angle (Fig. 4) and SPR (Fig. 6) analysis, suggest that the interplay between the dithiolane and the azobenzene moiety interacting with the $\mathrm{Au}$ substrate plays an important role in defining the SAM adsorption process for AzoSS, and an inherently different interplay to the thiol and azobenzene in AzoSH, which follows classical alkyl thiol absorption kinetics. ${ }^{27}$

Thus, it is clear that the adsorption kinetics of the AzoSS and AzoSH SAM formation are significantly different, which may be accounted for by the competing interactions of the azobenzene moiety and either the thiol or the dithiolane for the gold surface. If we consider that the RS-Au bond forms more rapidly from a thiol than it does from a disulfide or dithiolane as previously suggested by Whitesides and co-workers, ${ }^{31}$ the initial physisorption of the azobenzenes in a lying-down configuration on the gold surface may persist for longer with the Azoss than the AzoSH. This behaviour allows a multilayer of AzoSS molecules to form by virtue of van der Waals and $\pi-\pi$ interactions between surface physisorbed AzoSS and those approaching the interface. Indeed, the high thickness of AzoSS SAMs at lower formation times (Stage I) supports such a hypothesis when coupled to the rapid decline in thickness, such that at low formation times for AzoSS (Stage I) a transient multilayer adsorption process occurs with the azobenzenes lying-down on the gold surface before the $\mathrm{S}-\mathrm{S}$ bond can cleave and form the $\mathrm{Au}-\mathrm{S}$ bond. This explanation is consistent with the literature ${ }^{32-34}$ on the growth of SAMs in which the SAM formation phases (initial physisorbed, lying-down phase, followed by a chemisorbed, standing-up phase) are determined, among several others parameters, by the structure of the SAM molecule, i.e. headgroup, backbone and endgroup.

A striking difference between the ellipsometry and SPR results is that in the former characterisation, the initial adsorption of AzoSS molecules on the gold surface is much more 


\section{AzoSS}
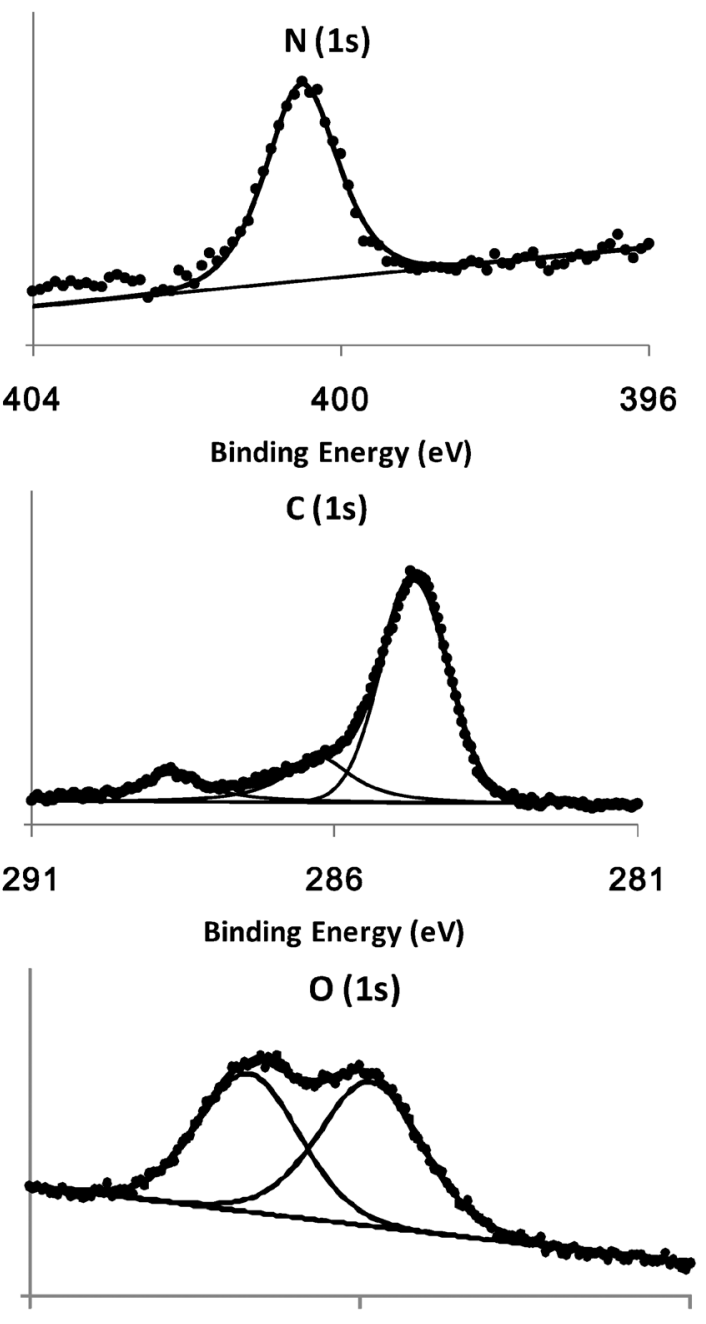

536

532

Binding Energy (eV)

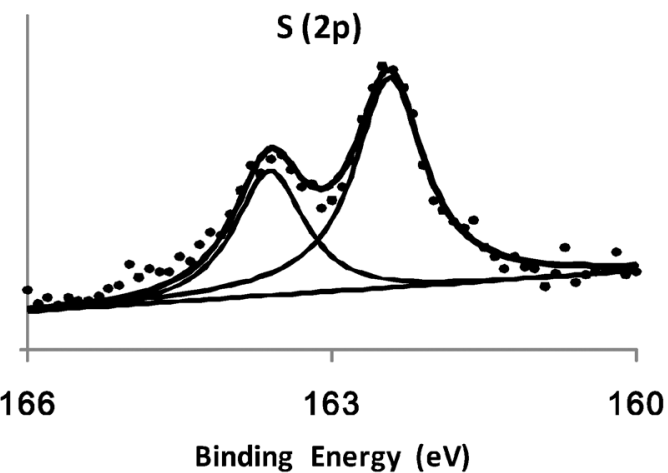

\section{AzoSH}

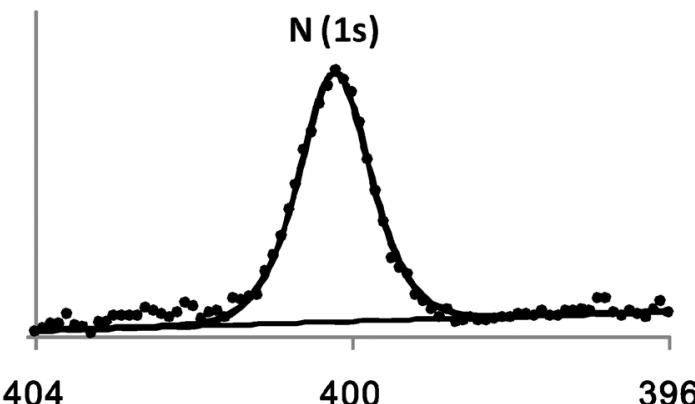

Binding Energy (eV)

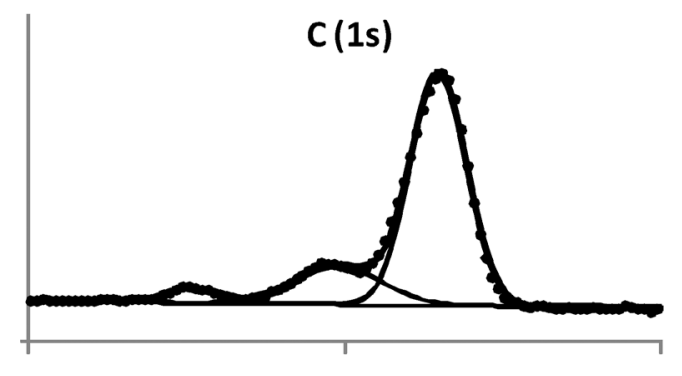

291

286

281

Binding Energy (eV)

$O$ (1s)

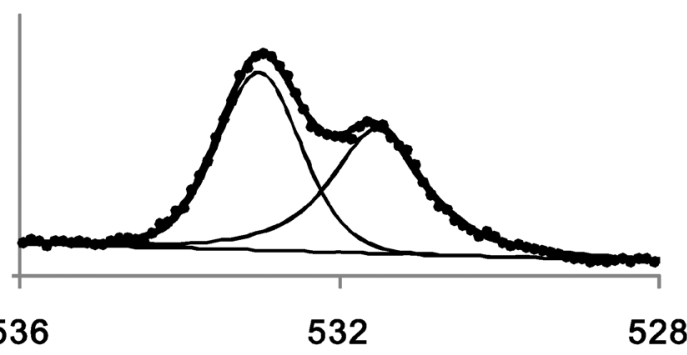

Binding Energy (eV)

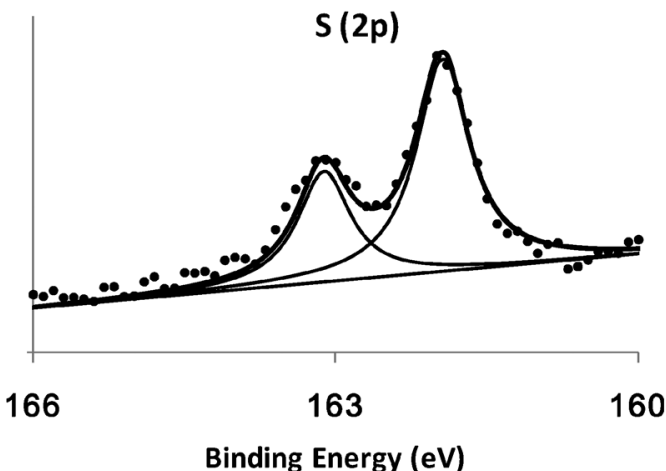

Fig. $5 \mathrm{~N}(1 \mathrm{~s}), \mathrm{C}(1 \mathrm{~s}), \mathrm{O}(1 \mathrm{~s})$ and S (2p) XPS spectra of AzoSS and AzoSH SAMs, together with the corresponding fits.

pronounced and the desorption occurs more slowly. Ellipsometry results demonstrate that the desorption occurs for a period of $5.5 \mathrm{~h}$ while SPR desorption takes place for $30 \mathrm{~min}$. The differences obtained by ellipsometry and SPR are believed to be related to the flow-induced shear stress applied during the
SPR analysis which is not present during the preparation of the SAM surfaces used for ellipsometry measurements. These findings suggest that flow-induced shear stress may prevent to a certain extent lateral stacking of the AzoSS molecules on the surface. Despite the use of different SAM preparation conditions 


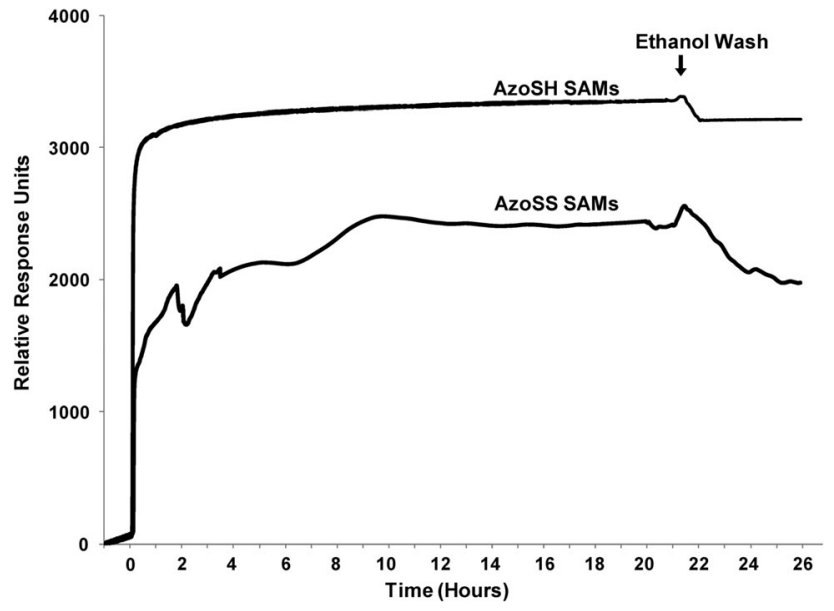

Fig. 6 SPR sensorgram traces showing the formation of the AzoSS and AZoSH SAMs in real time for $21 \mathrm{~h}$. Following SAM formation, the surfaces were washed with ethanol.

for both analyses, both ellipsometry and SPR clearly illustrate the differences in kinetics of AzoSS and AzoSH SAM formation.
The UV/Vis spectra of both AzoSS and AzoSH SAMs (Fig. 7) were investigated as a function of time. Post SAM formation samples were washed and dried, then immediately analysed using UV/Vis absorption spectroscopy. The UV/Vis spectra of AzoSS SAMs show the three formation stages (I-III), in accordance with those seen by ellipsometry and contact angle. At low formation times (0.5-6 h, Stage I), $\lambda_{\max }$ (Table 1 ) is hypsochromically shifted with respect to $\lambda_{\max }=329 \mathrm{~nm}$ in an ethanolic solution, which can be interpreted in terms of strong intermolecular interactions in the film leading to formation of H-aggregates. In Stage II (6-12 h of SAM formation), $\lambda_{\max }$ is still hypsochromically shifted with respect to the solution value (329 $\mathrm{nm})$, but the hypsochromic shifts are generally not as large as in Stage I, suggesting that the degree of aggregation is reduced with increasing formation time. In Stage III ( $24 \mathrm{~h}$ of SAM formation), the spectrum revealed an intense $\pi-\pi^{*}$ absorption band at $\approx 329 \mathrm{~nm}$, which is in agreement with the solution value, therefore indicating that azobenzene is not aggregated.

AzoSH UV/Vis spectra are characterized by two absorption bands (Fig. 7), with the absorption at lower wavelengths

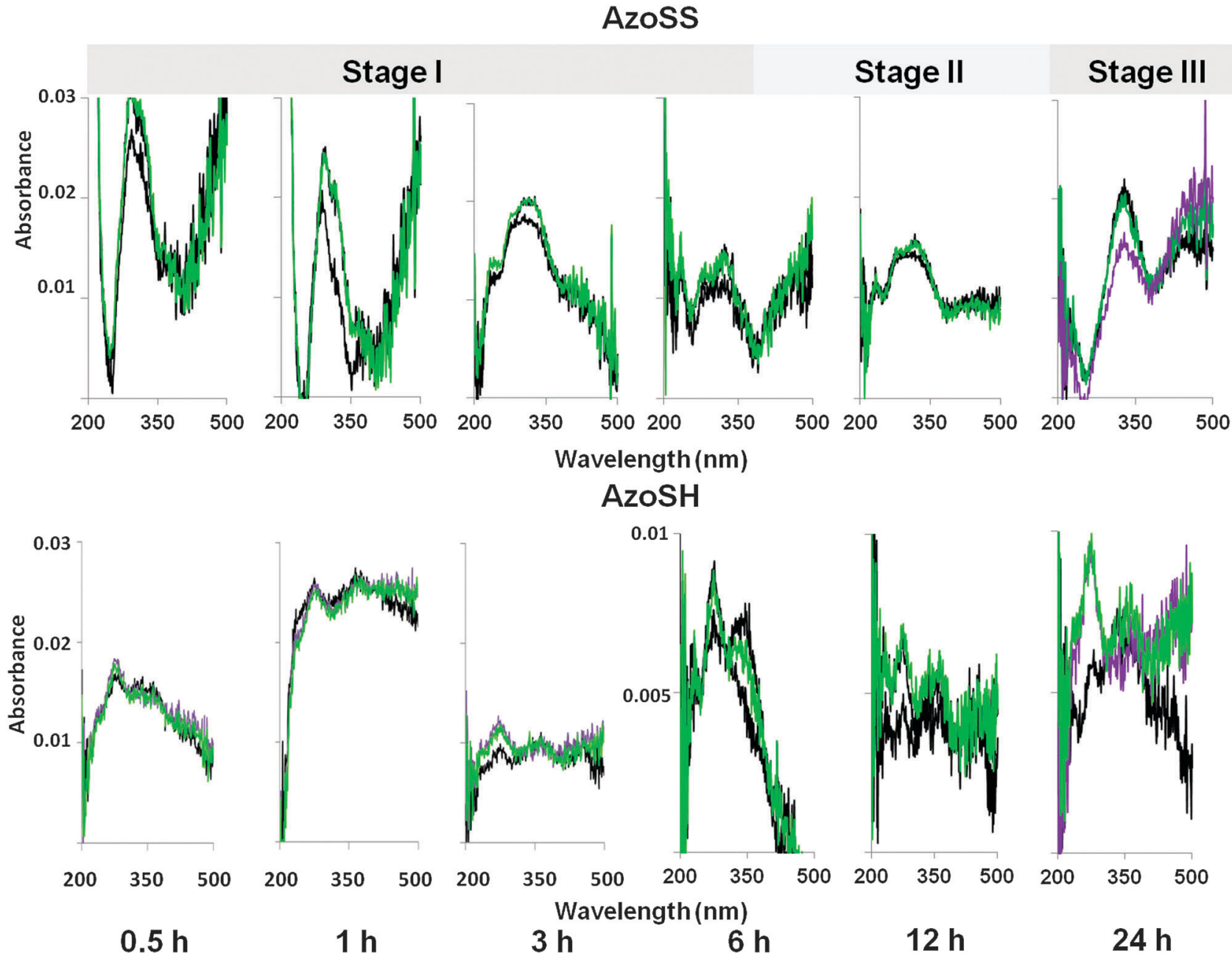

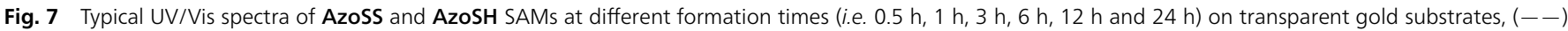

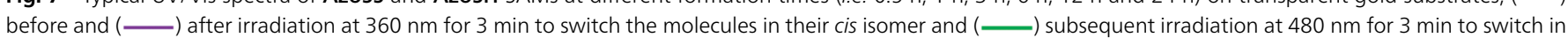
the trans isomer. 
Table $1 \lambda_{\max }$ of AzoSS and AzoSH SAM samples at different formation times

\begin{tabular}{llll}
\hline & & AzoSS & \\
\cline { 3 - 4 } Time $(\mathrm{h})$ & $\lambda_{\max }(\mathrm{nm})$ & $\lambda_{\max } 1(\mathrm{~nm})$ & $\lambda_{\max } 2(\mathrm{~nm})$ \\
\hline 0.5 & 294 & 275 & - \\
1 & 287 & 278 & 361 \\
3 & 318 & 273 & 360 \\
6 & 322 & 277 & 349 \\
12 & 323 & 274 & 346 \\
24 & 329 & 279 & 344 \\
\hline
\end{tabular}

(273-279 nm, $\lambda_{\max } 1$ in Table 1) representing H-aggregates that are strongly packed on the surface since they are significantly hypsochromically shifted from the solution value of $360 \mathrm{~nm}$. For lower formation times $(0.5-3 \mathrm{~h})$, the absorption at higher wavelengths $\left(\lambda_{\max } 2\right.$ in Table 1$)$ is similar to the solution value, indicating that some of the azobenzene molecules are adsorbed on the surface in a non-aggregated state. By increasing the time of SAM formation, $\lambda_{\max } 2$ increasingly shifted to lower wavelengths, representing the formation of $\mathrm{H}$-aggregates with increased order of the monolayer. ${ }^{35,36}$

The photoisomerization of both AzoSS and AzoSH SAMs was also investigated as a function of SAM formation time, using the samples discussed above. In order to examine reversible changes in the molecular conformation and the resulting spectroscopic features of the AzoSS and AzoSH SAMs under UV and Vis light irradiation, SAMs were subjected to alternating irradiation for $3 \mathrm{~min}$ with UV and Vis light and the UV/Vis absorption spectroscopy employed to follow such a process (Fig. 7). It should be mentioned that for the samples where a photoreaction was achieved (i.e. AzoSS SAMs formed over $24 \mathrm{~h}$ ), the photostationary equilibrium by UV and Vis irradiation was reached after $2 \mathrm{~min}$.

For AzoSS SAMs, at low formation times ( $0.5 \mathrm{~h}$ and $1 \mathrm{~h})$, the samples show optical activity atypical of azobenzenes. Irradiation with UV light increases absorption, while exposure to Vis light had little further effect, suggesting that irradiation induces aggregation. The samples having formation times between $3 \mathrm{~h}$ and $12 \mathrm{~h}$ exhibit a small degree of isomerization. In contrast, at $24 \mathrm{~h}$ AzoSS SAMs, upon UV light irradiation, a significant reduction in the $\pi-\pi^{*}$ absorption band at $329 \mathrm{~nm}$ was observed, indicating that azobenzene molecules undergo a conformation change from the trans to the cis form. Subsequent visible light irradiation $(436 \mathrm{~nm})$ gave rise to cis-to-trans back isomerization, maximizing the $\pi-\pi^{*}$ absorption band at $\approx 329 \mathrm{~nm}$. Generally, for AzoSH SAMs, exposure to UV results in an increase in the absorption of $\lambda_{\max } 1$ corresponding to a higher amount of $\mathrm{H}$-aggregates that are strongly packed on the surface. The absorption of $\lambda_{\max } 1$ remains unchanged upon Vis irradiation. UV and Vis irradiation has a small effect on the absorption of $\lambda_{\max } 2$ for times of SAM formation between 6 and $12 \mathrm{~h}$. However, by $24 \mathrm{~h}$ of SAM formation the degree of isomerization on the AzoSH SAMs is completely suppressed.

\section{Conclusions}

We have compared the formation kinetics and photoisomerization properties of azobenzene SAMs comprising either a thiol or a dithiolane headgroup. The azobenzene dithiolane SAMs were found to follow a three-stage assembly process, with ellipsometry, contact angle, SPR and UV/Vis spectroscopy data suggesting that the AzoSS moieties initially adsorb on the surface as multilayer aggregates. The results highlight the critical role of time of SAM formation in dictating $\mathrm{H}$-aggregation and photoisomerization on AzoSS SAMs. AzoSS SAMs are aggregated at low formation times and the degree of aggregation decreases with increasing formation time, until non-aggregated SAMs are formed after $24 \mathrm{~h}$. Azobenzene, within AzoSH SAMs are generally $\mathrm{H}$-aggregated, irrespective of formation time. While SAMs of AzoSH do not exhibit photoisomerization, clear and highly reversible photoinduced effects are observed for AzoSS SAMs.

\section{Experimental}

\section{Chemicals and materials}

Commercially available chemicals and solvents were purchased from Aldrich Chemicals and Fisher Chemicals and were used as received. Thin-layer chromatography (TLC) was carried out on aluminium plates coated with silica gel 60 F254 (Merck 5554). The TLC plates were either air-dried and analysed under a short wave UV lamp $(254 \mathrm{~nm})$ or developed in either permanganate solution and heat-dried. Column chromatographic separations were performed using silica gel 120 (ICN Chrom 32-63, 60 A).

\section{Synthesis of AzoSH and AzoSS}

(E)-tert-Butyl 4-((4-hydroxyphenyl)diazenyl)benzoate (1). A solution of $\mathrm{NaNO}_{2}(1.22 \mathrm{~g}, 17.68 \mathrm{mmol})$ in $\mathrm{H}_{2} \mathrm{O}(3.4 \mathrm{~mL})$ was added dropwise to a solution of 4-aminobenzoic acid tert-butyl ester $(3.40 \mathrm{~g}, 17.62 \mathrm{mmol})$ in $1 \mathrm{M} \mathrm{HCl}(10 \mathrm{~mL})$ at $0{ }^{\circ} \mathrm{C}$. The subsequent diazotised solution was added dropwise to a chilled solution of phenol (1.66 g, $17.66 \mathrm{mmol})$ and $\mathrm{KOH}(1.97 \mathrm{~g}$, $35.18 \mathrm{mmol})$ in $\mathrm{MeOH}(21 \mathrm{~mL})$. The resultant reaction mixture was further stirred for $4 \mathrm{~h}$. The reddish/orange precipitate was collected through suction filtration to yield a reddish/orange solid (4.22 g, 85\%). ${ }^{1} \mathrm{H}$ NMR (300 $\left.\mathrm{MHz}, \mathrm{CDCl}_{3}, \mathrm{Me}_{4} \mathrm{Si}, 25{ }^{\circ} \mathrm{C}\right)$ $\delta_{\mathrm{H}} \operatorname{ppm} 8.11(\mathrm{~d}, 2 \mathrm{H}, J=8.45 \mathrm{~Hz}), 7.90(\mathrm{~d}, 2 \mathrm{H}, J=8.75 \mathrm{~Hz}), 7.88$ $(\mathrm{d}, 2 \mathrm{H}, J=8.45 \mathrm{~Hz}), 6.97(\mathrm{~d}, 2 \mathrm{H}, J=8.75 \mathrm{~Hz}, \operatorname{Ar} H), 1.64(\mathrm{~s}, 9 \mathrm{H})$; ${ }^{13} \mathrm{C}$ NMR $\left(75 \mathrm{MHz}, \mathrm{CDCl}_{3}, \mathrm{Me}_{4} \mathrm{Si}, 25{ }^{\circ} \mathrm{C}\right) \delta_{\mathrm{C}} \mathrm{ppm} \mathrm{164.2,} \mathrm{157.1,}$ $151.8,144.0,128.9,124.0,120.7,114.5,80.4,26.7 ; \mathrm{m} / z$ (ESMS): $321\left([\mathrm{M}+\mathrm{Na}]^{+}, 100 \%\right) ; \mathrm{m} / \mathrm{z}$ (HRMS): found 321.1217. Calc. mass for $\mathrm{C}_{17} \mathrm{H}_{18} \mathrm{~N}_{2} \mathrm{O}_{3} \mathrm{Na}$ : 321.1215 .

$S$-(6-Bromohexyl) ethanethioate (2). A solution of 6-bromo-1hexene $(2.00 \mathrm{~g}, 12.27 \mathrm{mmol})$, thioacetic acid $(1.87 \mathrm{~g}$, $24.61 \mathrm{mmol})$ and AIBN (catalytic amount) in PhMe $(20 \mathrm{~mL})$ was refluxed for $2 \mathrm{~h}$. The resultant reaction mixture was allowed to cool to room temperature and saturated $\mathrm{NaHCO}_{3}$ aqueous solution was added and the organic layer was extracted with DCM $(3 \times 20 \mathrm{~mL})$. The combined organic layers were dried $\left(\mathrm{MgSO}_{4}\right)$, filtered and concentrated in vacuo. The crude product was purified by column chromatography (eluent: hexane) to yield a colourless oil $(2.00 \mathrm{~g}, 68 \%) .{ }^{1} \mathrm{H}$ NMR $\left(300 \mathrm{MHz}, \mathrm{CDCl}_{3}\right.$, $\left.\mathrm{Me}_{4} \mathrm{Si}, 25^{\circ} \mathrm{C}\right) \delta_{\mathrm{H}} \mathrm{Ppm} 3.34(\mathrm{t}, 2 \mathrm{H}, J=6.14 \mathrm{~Hz}), 2.80(\mathrm{t}, 2 \mathrm{H}, J=$

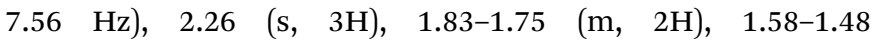
$(\mathrm{m}, 2 \mathrm{H}), 1.44-1.29(\mathrm{~m}, 4 \mathrm{H}) ;{ }^{13} \mathrm{C}$ NMR $\left(75 \mathrm{MHz}, \mathrm{CDCl}_{3}, \mathrm{Me}_{4} \mathrm{Si}\right.$, $\left.25{ }^{\circ} \mathrm{C}\right) \delta_{\mathrm{C}} \mathrm{ppm} 195.9,33.7,32.6,30.6,29.3,28.9,27.9,27.6 ; \mathrm{m} / \mathrm{z}$ 
(ESMS): 261 ([M + Na $\left.]^{+}, 100 \%\right), 263\left([\mathrm{M}+\mathrm{Na}]^{+}, 100 \%\right) ; m / z$ (HRMS): found 260.9923. Calc. mass for $\mathrm{C}_{8} \mathrm{H}_{15} \mathrm{OSBrNa}$ : 260.9925 .

(E)-tert-Butyl 4-((4-((5-(1,2-dithiolan-3-yl)pentanoyl)oxy)phenyl)diazenyl)benzoate (AzoSS). To a stirred solution of thioctic acid (2.00 g, $9.60 \mathrm{mmol})$ and DMAP $(0.06 \mathrm{~g}, 0.48 \mathrm{mM})$ in anhydrous DCM, at room temperature, $1(0.72 \mathrm{~g}, 2.40 \mathrm{mmol})$ was added. The reaction mixture was cooled to $0{ }^{\circ} \mathrm{C}$ in an ice bath and DCC $(1.00 \mathrm{~g}$, $4.80 \mathrm{mM}$ ) added and stirred for $10 \mathrm{~min}$. The ice bath was then removed and the reaction mixture brought to room temperature and stirred overnight. The crude reaction mixture was washed with $\mathrm{HCl}(1 \mathrm{M})(1 \times 100 \mathrm{~mL})$ followed by $5 \% \mathrm{NaHCO}_{3}(1 \times 100 \mathrm{~mL})$ and finally with water $(1 \times 100 \mathrm{~mL})$. The organic layer was then dried $\left(\mathrm{MgSO}_{4}\right)$ filtered and concentrated in vacuo. The crude product was purified by column chromatography ( $1 \% \mathrm{MeOH}$ in DCM) to yield a orange solid ( $0.70 \mathrm{~g}, 60 \%)$. Elemental analysis found: C, 61.88\%; $\mathrm{H}, 5.97 \%$; N, 5.52\%. Calc. for $\mathrm{C}_{25} \mathrm{H}_{30} \mathrm{~N}_{2} \mathrm{O}_{4} \mathrm{~S}_{2}$ : C, 61.7\%; H, 6.2\%; $\mathrm{N}, 5.8 \% .{ }^{1} \mathrm{H}$ NMR $\left(300 \mathrm{MHz}, \mathrm{CDCl}_{3}, \mathrm{Me}_{4} \mathrm{Si}, 25{ }^{\circ} \mathrm{C}\right) \delta_{\mathrm{H}} \mathrm{ppm} 8.41$ $(\mathrm{d}, J=8.60 \mathrm{~Hz}, 2 \mathrm{H}), 8.27$ (d, $J=8.60 \mathrm{~Hz}, 2 \mathrm{H}), 8.19(\mathrm{~d}, J=8.60 \mathrm{~Hz}, 2 \mathrm{H})$, $7.54(\mathrm{~d}, J=8.60 \mathrm{~Hz}, 2 \mathrm{H}), 3.89(\mathrm{~m}, 1 \mathrm{H}), 3.45(\mathrm{~m}, 2 \mathrm{H}), 2.90(\mathrm{t}, 2 \mathrm{H})$, 2.05 (m, 4H), 1.90 (s, 9H); NMR (75 MHz, $\mathrm{CDCl}_{3}, \mathrm{Me}_{4} \mathrm{Si}, 25{ }^{\circ} \mathrm{C}$ ) $\delta_{\mathrm{C}}$ ppm 132.3, 126.2, 124.4, 124.2, 58.1, 42.1, 40.4, 36.5, 36.0, 26.4; $\mathrm{m} / z$ (ESMS): $509.2\left(\left[\mathrm{M}+\mathrm{Na}^{+}\right]^{+}, 100 \%\right)$.

(E)-tert-Butyl 4-((4-((6-(acetylthio)hexyl)oxy)phenyl)diazenyl)benzoate (3). A slurry of $1(1.00 \mathrm{~g}, 3.34 \mathrm{mmol}), 2(1.20 \mathrm{~g}$, $5.02 \mathrm{mmol})$, and $\mathrm{K}_{2} \mathrm{CO}_{3}(0.92 \mathrm{~g}, 6.67 \mathrm{mmol})$ in acetone $(50 \mathrm{~mL})$ was refluxed for $16 \mathrm{~h}$. The resultant reaction mixture was allowed to cool to room temperature and $\mathrm{K}_{2} \mathrm{CO}_{3}$ was filtered off and the solvent removed in vacuo. The crude solid was adsorbed onto silica and purified by column chromatography (gradient elution; 0-20\% EtOAc in hexane, increase in increments of $10 \%$ after $100 \mathrm{~mL}$ of eluent) to yield a reddish orange solid (1.00 g, 66\%). ${ }^{1} \mathrm{H}$ NMR (300 $\mathrm{MHz}, \mathrm{CDCl}_{3}, \mathrm{Me}_{4} \mathrm{Si}$, $\left.25^{\circ} \mathrm{C}\right) \delta_{\mathrm{H}} \operatorname{ppm} 8.04(\mathrm{~d}, 2 \mathrm{H}, J=8.76 \mathrm{~Hz}), 7.87(\mathrm{~d}, 2 \mathrm{H}, J=8.99 \mathrm{~Hz})$, $7.81(\mathrm{~d}, 2 \mathrm{H}, J=8.76 \mathrm{~Hz}), 6.94(\mathrm{~d}, 2 \mathrm{H}, J=8.99 \mathrm{~Hz}), 3.98(\mathrm{t}, 2 \mathrm{H}, J=$ $6.69 \mathrm{~Hz}), 2.83(\mathrm{t}, 2 \mathrm{H}, J=7.86 \mathrm{~Hz}), 2.26(\mathrm{~s}, 3 \mathrm{H}), 1.81-1.69(\mathrm{~m}, 2 \mathrm{H})$, $1.55(\mathrm{~s}, 9 \mathrm{H}), 1.50-1.34(\mathrm{~m}, 6 \mathrm{H}) ;{ }^{13} \mathrm{C} \mathrm{NMR} \mathrm{(75} \mathrm{MHz}, \mathrm{CDCl}_{3}$, $\left.\mathrm{Me}_{4} \mathrm{Si}, 25{ }^{\circ} \mathrm{C}\right) \delta_{\mathrm{C}} \operatorname{ppm~165.3,~162.2,~155.1,~146.9,~133.1,~130.4,~}$ 125.1, 122.2, 114.8, 81.3, 68.2, 30.7, 29.5, 29.0, 28.5, 28.2, 25.6; $\mathrm{m} / z$ (ESMS): $479\left([\mathrm{M}+\mathrm{Na}]^{+}, 100 \%\right) ; \mathrm{m} / z$ (HRMS): found 479.1972. Calc. mass for $\mathrm{C}_{25} \mathrm{H}_{32} \mathrm{~N}_{2} \mathrm{O}_{4} \mathrm{SNa}$ : 479.1980.

(E)-tert-Butyl 4-((4-((6-mercaptohexyl)oxy)phenyl)diazenyl)benzoate (AzoSH). A solution of $3(1.00 \mathrm{~g}, 2.19 \mathrm{mmol})$ in $0.1 \mathrm{M} \mathrm{HCl}$ methanolic solution $(100 \mathrm{~mL})$ was refluxed for $4 \mathrm{~h}$ under a $\mathrm{N}_{2}$ atmosphere. The resultant reaction mixture was concentrated in vacuo and the crude solid was adsorbed onto silica and purified by column chromatography (gradient elution; 0-20\% EtOAc in hexane, increase in increments of $10 \%$ after $100 \mathrm{~mL}$ of eluent). The solvent was removed and the resultant solid was recrystallised from EtOH to yield reddish orange solid $(0.65 \mathrm{~g}, 71 \%)$. Elemental analysis found: $\mathrm{C}$, $66.35 \% ; \mathrm{H}, 7.50 \% ; \mathrm{N}, 6.77 \%$. Calc. for $\mathrm{C}_{23} \mathrm{H}_{30} \mathrm{~N}_{2} \mathrm{O}_{3} \mathrm{~S}: \mathrm{C}$, $66.64 \%$; H, 7.31\%; N, 7.29\%; ${ }^{1} \mathrm{H}$ NMR $\left(300 \mathrm{MHz}, \mathrm{CDCl}_{3}, \mathrm{Me}_{4} \mathrm{Si}\right.$, $\left.25{ }^{\circ} \mathrm{C}\right) \delta_{\mathrm{H}} \operatorname{ppm} 8.04(\mathrm{~d}, 2 \mathrm{H}, J=8.07 \mathrm{~Hz}, \operatorname{Ar} H), 7.87(\mathrm{~d}, 2 \mathrm{H}, J=$ $9.00 \mathrm{~Hz}), 7.81(\mathrm{~d}, 2 \mathrm{H}, J=8.07 \mathrm{~Hz}), 6.94(\mathrm{~d}, 2 \mathrm{H}, J=9.00 \mathrm{~Hz}), 3.98$ $(\mathrm{t}, 2 \mathrm{H}, J=6.42 \mathrm{~Hz}), 2.80(\mathrm{q}, 2 \mathrm{H}, J=7.49 \mathrm{~Hz}), 1.82-1.73(\mathrm{~m}, 2 \mathrm{H})$, 1.55 (s, 9H), 1.55-1.48 (m, 2H), 1.44-1.42 (m, 4H), $1.28(\mathrm{t}, 2 \mathrm{H}$,
$J=7.49 \mathrm{~Hz}) ;{ }^{13} \mathrm{C} \mathrm{NMR}\left(75 \mathrm{MHz}, \mathrm{CDCl}_{3}, \mathrm{Me}_{4} \mathrm{Si}, 25{ }^{\circ} \mathrm{C}\right) \delta_{\mathrm{C}} \mathrm{ppm}$ 165.3, 162.2 , 155.1, 146.9, 133.1, 130.4, 125.1, 122.2, 114.8, 81.3, 68.2 , 33.9, 29.1 28.2, 28.1, 25.5, 24.5; $\mathrm{m} / \mathrm{z}$ (ESMS): $415\left([\mathrm{M}+\mathrm{H}]^{+}\right.$, $100 \%) ; m / z$ (HRMS): found 415.2048. Calc. mass for $\mathrm{C}_{23} \mathrm{H}_{31} \mathrm{~N}_{2} \mathrm{O}_{3} \mathrm{~S}$ 415.2055 .

\section{Compound characterisation}

Nuclear magnetic resonance spectroscopy. ${ }^{1} \mathrm{H}$ Nuclear Magnetic Resonance (NMR) spectra were recorded on a Bruker AC 300 (300.13 MHz) spectrometer. ${ }^{13} \mathrm{C}$ NMR spectra were recorded on a Bruker AV 300 (75.5 MHz) using the pendent pulse sequences. In both techniques all chemical shifts are calibrated to the $\mathrm{SiMe}_{4}$ peak and quoted in ppm upfield of the reference. Analysis was performed in either deuterated chloroform $\left(\mathrm{CDCl}_{3}\right)$. The coupling constants of ${ }^{1} \mathrm{H}$ NMR are expressed in Hertz $(\mathrm{Hz})$ with multiplicities abbreviated as follows; $\mathrm{s}=$ singlet, $\mathrm{d}=$ doublet, $\mathrm{t}=$ triplet and $\mathrm{m}=$ multiplet.

Mass spectroscopy. Electrospray Mass Spectroscopy (ESMS) and High Resolution Mass Spectroscopy (HRMS) were performed on a Micromass Time of Flight (TOF) using methanol as the running solvent.

Elemental analysis. Elemental analysis was performed on a Carlo Erba EA 1110 (C, H, N) instrument. Reported results are an average of two runs for each compound.

\section{SAM characterisation}

Preparation of SAMs. Polycrystalline gold substrates were purchased from George Albert PVD, Germany and consisted either of a $50 \mathrm{~nm}$ gold layer (used for ellipsometry, contact angle and XPS analysis) or a $20 \mathrm{~nm}$ transparent gold layer (used for UV spectroscopy), deposited onto a glass covered with a thin adhesion layer of titanium. The $\mathrm{Au}$ substrates were cleaned by immersion in piranha solution $\left(70 \% \mathrm{H}_{2} \mathrm{SO}_{4}: 30 \% \mathrm{H}_{2} \mathrm{O}_{2}\right)$ at room temperature for $10 \mathrm{~min}$, rinsing with Ultra High Pure (UHP) $\mathrm{H}_{2} \mathrm{O}$ and then HPLC grade EtOH thoroughly for 1 min. (Caution: piranha solution reacts violently with all organic compounds and should be handled with care.) Immediately after cleaning, the substrates were immersed in freshly prepared ethanolic solutions of AzoSS (0.0625 mM) and AzoSH $(0.0625 \mathrm{mM})$ in the trans form.

Post-immersion in the SAM forming solution, the substrates were rinsed with HPLC EtOH and dried under a stream of $\mathrm{N}_{2}$.

Ellipsometry. The ellipsometer used is a Jobin Yvon UVISEL with a broadband xenon light source. The light source's angle of incidence and wavelength range, throughout the experiment, was $70^{\circ}$ and $280-820 \mathrm{~nm}$, respectively. Calibration of the ellipsometer and alignment of the polariser and detector was performed through employment of an aluminium reference sample, with a thermally grown aluminium oxide $\left(\mathrm{Al}_{2} \mathrm{O}_{3}\right)$ layer. The ellipsometric parameters, $\Delta$ and $\psi$, were recorded for both the clean bare substrates and for the substrates on which SAMs were formed. All measurements were made under conditions of ambient temperature, pressure and humidity. DeltaPsi software was used to determine the film thickness. Raw data were modelled using a Cauchy transparent model over the whole data range (280$820 \mathrm{~nm}$ ). Reliability of the model was tested/calibrated using SAMs 
formed from tetra-, hexa- and octa-decanethiols. Measurements reported are an average of at least two independently prepared samples with an average of six readings per sample, taken in different places ensuring not to take measurements on visibly defective sites.

Contact angle. Measurements were preformed with UHQ $\mathrm{H}_{2} \mathrm{O}$ on a homemade manually operated goniometer. A $25 \mu \mathrm{L}$ gas tight syringe (Hamilton) was used to add and remove droplets to the surface, droplets were typically of $\approx 15 \mu \mathrm{L}$. The drop was recorded using a Hitachi ${ }^{\mathrm{TM}}$ Charged Coupled Device (CCD) camera, connected to a personal computer by USB in order to capture a video of the advancing and receding angles. Angles were analysed at the three phase boundary using the commercially available video analysis software FTA (First Ten Angstroms) version 1.96. Contact angles were determined using the dynamic sessile drop method, using UHQ $\mathrm{H}_{2} \mathrm{O}$. The frame rate of video capture was 4 frames per second and 50 frames were collected. Measurements reported are an average of two independently prepared samples with an average of five readings per sample, taken in different places. All measurements were taken under ambient conditions of temperature, pressure and humidity. The errors reported are the standard errors of the mean.

X-ray Photoelectron Spectroscopy (XPS). X-ray Photoelectron Spectroscopy (XPS) spectra were obtained on the VG ESCAlab 250 instrument based at the Leeds EPSRC Nanoscience and Nanotechnology Research Equipment Facility (LENNF) at the University of Leeds, UK. XPS experiments were carried out using a monochromatic Al $\mathrm{K} \alpha \mathrm{X}$-ray source $(1486.7 \mathrm{eV})$ and a take off angle of $90^{\circ}$. High-resolution scans of $\mathrm{N}(1 \mathrm{~s}), \mathrm{S}(2 \mathrm{p}), \mathrm{O}$ (1s), C (1s) and Au (4f) were recorded using a pass energy of $150 \mathrm{eV}$ at a step size of $0.05 \mathrm{eV}$. Fitting of XPS peaks was performed using the Avantage V2.2 processing software. Sensitivity factors used in this study were: $\mathrm{N}(1 \mathrm{~s}), 1.73$; S (2p), 2.08; C (1s), 1.00; O (1s) 2.8; Au (4f $\left.f_{7 / 2}\right), 9.58 ; \mathrm{Au}\left(4 \mathrm{f}_{5 / 2}\right), 7.54$.

UV/Vis spectroscopy. The UV/Vis absorption spectra of the solution and SAMs were obtained using a double beam Cary $5000 \mathrm{UV} / \mathrm{Vis}$ spectrometer. Solution spectra were obtained by measuring the absorption of AzoSS and AzoSH in ethanol $(0.0625 \mathrm{mM})$ in a quartz cell with a path length of $1 \mathrm{~cm}$. Pure ethanol was used as a reference solution. SAM spectra were obtained with a clean gold substrate in the reference beam. Photoirradiation of the samples was carried out with a $200 \mathrm{~W}$ Mercury-Xenon Arc Lamp using filters for UV light centred at $\lambda=365 \mathrm{~nm}$ and for visible light centred at $\lambda=436 \mathrm{~nm}$. SAMs were analysed immediately after formation and subjected to a cycle of irradiation of $3 \mathrm{~min}$ exposures to UV or Vis light. Between exposure to light and spectroscopic readings the samples were kept in the dark.

Surface Plasmon Resonance (SPR) spectroscopy. The SPR measurements were performed on a Reichert SR7000DC Dual Channel Spectrometer (Buffalo, NY, USA) at $15{ }^{\circ} \mathrm{C}$. A twochannel flow cell with two independent parallel flow channels was used to carry out the SAM kinetic experiments. A goldcoated SPR chip was placed on the top side of the prism using index-matching oil. After a baseline signal was established by allowing degassed HPLC ethanol to flow at a rate of $10 \mu \mathrm{L} \mathrm{min}{ }^{-1}$ through the sensor, freshly prepared ethanolic solutions of the AzoSS (0.0625 mM) or AzoSH (0.0625 mM) in the trans form were allowed to flow over the surface for $21 \mathrm{~h}$ at a flow rate of

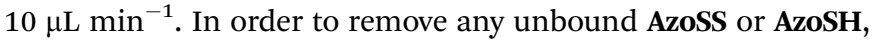
the sensor chips were washed with degassed ethanol at a flow rate of $50 \mu \mathrm{L} \mathrm{min}{ }^{-1}$.

\section{Acknowledgements}

We acknowledge the Leverhulme Trust (F/00094/AW) for financial support. We would like to thank the University of Leeds EPSRC Nanoscience and Nanotechnology Facility (LENNF) for access to the XPS. This research was in part supported through Birmingham Science City: Innovative Uses for Advanced Materials in the Modern World (West Midlands Centre for Advanced Materials Project 2), supported by Advantage West Midlands (AWM) and part funded by the European Regional Development Fund (ERDF).

\section{References}

1 P. M. Mendes, Chem. Soc. Rev., 2008, 37, 2512.

2 S. Diegoli, C. A. E. Hamlett, S. J. Leigh, P. M. Mendes and J. A. Preece, Proc. Inst. Mech. Eng., Part G, 2007, 221, 589.

3 C. L. Yeung, P. Iqbal, M. Allan, M. Lashkor, J. A. Preece and P. M. Mendes, Adv. Funct. Mater., 2010, 20, 2657.

4 B. H. Northrop, A. B. Braunschweig, P. M. Mendes, W. R. Dichtel and J. F. Stoddart, in Handbook of Nanoscience, Engineering, and Technology, ed. W. A. Goddard, III, D. W. Brenner, S. E. Lyshevski and G. J. Iafrate, CRC Press, Boca Raton, 2nd edn, 2007, vol. 1.

5 F. Ercole, T. P. Davis and R. A. Evans, Polym. Chem., 2010, $1,37$.

6 Y. S. Dou, Y. Hu, S. A. Yuan, W. F. Wu and H. Tang, Mol. Phys., 2009, 107, 181.

7 C. M. Stuart, R. R. Frontiera and R. A. Mathies, J. Phys. Chem. A, 2007, 111, 12072.

8 A. Shaabani and M. Zahedi, J. Mol. Struct., 2000, 506, 257.

9 S. D. Evans, S. R. Johnson, H. Ringsdorf, L. M. Williams and H. Wolf, Langmuir, 1998, 14, 6436.

10 W. Freyer, D. Brete, R. Schmidt, C. Gahl, R. Carley and M. Weinelt, J. Photochem. Photobiol., A, 2009, 204, 102.

11 K. Tamada, J. Nagasawa, F. Nakanishi, K. Abe, T. Ishida, M. Hara and W. Knoll, Langmuir, 1998, 14, 3264.

12 K. Tamada, H. Akiyama and T. X. Wei, Langmuir, 2002, 18, 5239.

13 S. Sortino, S. Petralia, S. Conoci and S. Di Bella, J. Mater. Chem., 2004, 14, 811.

14 K. Tamada, H. Akiyama, T. X. Wei and S. A. Kim, Langmuir, 2003, 19, 2306.

15 M. N. Han, T. Honda, D. Ishikawa, E. Ito, M. Hara and Y. Norikane, J. Mater. Chem., 2011, 21, 4696.

16 M. Han, D. Ishikawa, T. Honda, E. Ito and M. Hara, Chem. Commun., 2010, 46, 3598.

17 M. Ito, T. X. Wei, P. L. Chen, H. Akiyama, M. Matsumoto, K. Tamada and Y. Yamamoto, J. Mater. Chem., 2005, 15, 478. 
18 S. Wagner, F. Leyssner, C. Kordel, S. Zarwell, R. Schmidt, M. Weinelt, K. Ruck-Braun, M. Wolf and P. Tegeder, Phys. Chem. Chem. Phys., 2009, 11, 6242.

19 U. Siemeling, C. Bruhn, F. Bretthauer, M. Borg, F. Trager, F. Vogel, W. Azzam, M. Badin, T. Strunskus and C. Woll, Dalton Trans., 2009, 8593.

20 U. Jung, O. Filinova, S. Kuhn, D. Zargarani, C. Bornholdt, R. Herges and O. Magnussen, Langmuir, 2010, 26, 13913.

21 T. Weidner, F. Bretthauer, N. Ballav, H. Motschmann, H. Orendi, C. Bruhn, U. Siemeling and M. Zharnikov, Langmuir, 2008, 24, 11691.

22 A. Ulman, Chem. Rev., 1996, 96, 1533.

23 H. L. Zhang, J. Zhang, H. Y. Li, Z. F. Liu and H. L. Li, Mater. Sci. Eng., C: Biomimetic Supramol. Syst., 1999, 8-9, 179.

24 K. J. Lee, F. Pan, G. T. Carroll, N. J. Turro and J. T. Koberstein, Langmuir, 2004, 20, 1812.

25 P. Iqbal, K. Critchley, J. Bowen, D. Attwood, D. Tunnicliffe, S. D. Evans and J. A. Preece, J. Mater. Chem., 2007, 17, 5097.

26 J. F. Moulder, W. F. Stickle, P. E. Sobol and K. D. Bomben, Handbook of X-ray Photoelectron Spectroscopy, Perkin-Elmer Corp, Eden Prairie, MN, USA, 1992.
27 C. D. Bain, E. B. Troughton, Y. T. Tao, J. Evall, G. M. Whitesides and R. G. Nuzzo, J. Am. Chem. Soc., 1989, 111, 321.

28 A. Pranzetti, S. Mieszkin, P. Iqbal, F. J. Rawson, M. E. Callow, J. A. Callow, P. Koelsch, J. A. Preece and P. M. Mendes, Adv. Mater., 2013, 25, 2181.

29 A. Pranzetti, S. Salauen, S. Mieszkin, M. E. Callow, J. A. Callow, J. A. Preece and P. M. Mendes, Adv. Funct. Mater., 2012, 22, 3672.

30 N. J. Cho, C. W. Frank, B. Kasemo and F. Hook, Nat. Protocols, 2010, 5, 1096.

31 C. D. Bain, H. A. Biebuyck and G. M. Whitesides, Langmuir, 1989, 5, 723.

32 Y. Ahn, J. K. Saha, G. C. Schatz and J. Jang, J. Phys. Chem. C, 2011, 115, 10668.

33 F. Schreiber, J. Phys.: Condens. Matter, 2004, 16, R881.

34 H. Kondoh, C. Kodama, H. Sumida and H. Nozoye, J. Chem. Phys., 1999, 111, 1175.

35 J. M. Kuiper and J. Engberts, Langmuir, 2004, 20, 1152.

36 T. Sato, Y. Ozaki and K. Iriyama, Langmuir, 1994, 10, 2363. 